\title{
Continuous seiche in bays and harbors
}

\author{
Joseph Park $^{1}$, Jamie MacMahan ${ }^{2}$, William V. Sweet ${ }^{3}$, and Kevin Kotun ${ }^{1}$ \\ ${ }^{1}$ National Park Service, 950 N. Krome Ave, Homestead, FL, USA \\ ${ }^{2}$ Naval Postgraduate School, 833 Dyer Rd., Monterey, CA, USA \\ ${ }^{3}$ NOAA, 1305 East West Hwy, Silver Spring, MD, USA
}

Correspondence to: Joseph Park (joseph_park@nps.gov)

Received: 4 September 2015 - Published in Ocean Sci. Discuss.: 8 October 2015

Revised: 14 February 2016 - Accepted: 18 February 2016 - Published: 7 March 2016

\begin{abstract}
Seiches are often considered a transitory phenomenon wherein large amplitude water level oscillations are excited by a geophysical event, eventually dissipating some time after the event. However, continuous small-amplitude seiches have been recognized which raises a question regarding the origin of continuous forcing. We examine six bays around the Pacific where continuous seiches are evident and, based on spectral, modal, and kinematic analysis, suggest that tidally forced shelf resonances are a primary driver of continuous seiches.
\end{abstract}

\section{Introduction}

It is long recognized that coastal water levels resonate. Resonances span the ocean as tides (Darwin, 1899), and bays as seiches (Airy, 1877; Chrystal, 1906). Bays and harbors offer refuge from the open ocean by effectively decoupling wind waves and swell from an anchorage, although offshore waves are effective in driving resonant modes in the infragravity regime at periods of $30 \mathrm{~s}$ to $5 \mathrm{~min}$ (Okihiro and Guza, 1996; Thotagamuwage and Pattiaratchi, 2014). At periods between $5 \mathrm{~min}$ and $2 \mathrm{~h}$, bays and harbors can act as efficient amplifiers (Miles and Munk, 1961).

Tides expressed on coasts are significantly altered by coastline and bathymetry; for example, continental shelves modulate tidal amplitudes and dissipate tidal energy (Taylor, 1919) such that tidally driven standing waves are a persistent feature on continental shelves (Webb, 1976; Clarke and Battisti, 1981). While tides are perpetual, seiches are often associated with transitory forcings and considered equally transitory. A thorough review of seiches is provided by Rabinovich (2009) wherein forcing mechanisms are known to include tsunamis, seismic ground waves, weather, nonlinear interactions of wind waves or swell, jet-like currents, and internal waves. With the exception of strong currents and internal tides, these forcings are episodic and consistent with a perception that seiches are largely transitory phenomena. However, records of continuous seiches extend back to at least Cartwright and Young (1974), who identified nearcontinuous 28 min seiches in Baltasound, Unst, and Lerwick in the Shetland Islands over a 16-week period in 1972. Their source hypothesis consisted of long waves from the North Sea trapped as edge waves along the island shelf and they noted large seiche amplitude modulations from fast-moving meteorological fronts.

Internal waves are known to influence seiches as demonstrated by Giese et al. (1990) who analyzed a 10-year time series of 6 min data at Magueyes Island, Puerto Rico, noting distinct seasonal and fortnightly distributions of shelf resonance and seiche amplitude, suggesting that stratification and its influence on internal waves generated by barotropic tides are important components of the observed seiche variability. Subsequent work led Giese and Chapman (1993) to conclude that, in locations where strong internal waves propagate to coastal regions, seiche sustenance is possible, and to question "Is this a general phenomenon to be expected wherever large coastal seiches are found, or is it specific to certain locations where large internal waves are known to occur?"

Golmen et al. (1994) studied a coastal embayment near the headland Stad in northwest Norway and identified permanent seiching superimposed on the semidiurnal tide, concluding that tidal forcing was the only possible energy source of the observed oscillations. Continuing their exploration of internal waves and seiching, Giese et al. (1998) examined harbor seiches at Puerto Princesa in the Philippines and found that 
periods of enhanced seiche activity are produced by internal bores generated by arrival of internal wave soliton packets from the Sulu Sea. However, as one would expect from soliton excitation, their analysis suggests that these seiches are not continually present.

Woodworth et al. (2005) studied water levels at Port Stanley in the Falkland Islands, identifying continuously present 87 and 26 min seiches with amplitudes of several centimeters. They also noted that amplitudes increase to $10 \mathrm{~cm}$ typically once or twice each month with no obvious seasonal dependence, and that these seiches have their maximum amplitudes nearly concurrently. Tidal spring-neap dependence was not observed, leading them to reject barotropic or internal tides as a cause; instead, they concluded that rapid changes in air pressure and local winds associated with troughs and fronts are likely driving these seiches.

Persistent seiching around the islands of Mauritius and Rodrigues was observed by Lowry et al. (2008) with distinct fortnightly and seasonal amplitude variations along the east and southeast coasts, but no fortnightly or seasonal variations along the west coast. Breaker et al. (2008) noticed continuously present seiches in Monterey Bay, leading Breaker et al. (2010) to consider several possible forcing mechanisms (edge waves, long-period surface waves, sea breeze, internal waves, microseisms, and small-scale turbulence) and to question whether or not "the excitation is global in nature". Subsequent analysis by Park et al. (2015) confirmed continuous oscillations in Monterey Bay over a 17.8-year record, and presented kinematic analysis discounting potential forcings of internal waves and microseisms while suggesting that a persistent mesoscale gyre situated outside the bay would be consistent with a jet-like forcing. However, jet-like currents are not a common feature along coastlines and could not be considered a global excitation of continuous oscillations.

Wijeratne et al. (2010) observed seiches with periods from 17 to 120 min persistent throughout the year at Trincomalee and Colombo, Sri Lanka, finding a strong fortnightly periodicity of seiche amplitude at Trincomalee on the east coast, but no fortnightly modulation on the west coast, rather a diurnal one attributed to weather forcing. Since it took a week for internal tides to travel from the Andaman Sea, the fortnightly modulations were strongest at neaps. It is notable that Wijeratne et al. (2010) attributed the $74 \mathrm{~min}$ seiche period at Colombo and the $54 \mathrm{~min}$ period at Galle to tidally forced shelf resonances.

Most recently, MacMahan (2015) analyzed 2 years of data (2011-2012) in Monterey Bay and Oil Platform Harvest, $270 \mathrm{~km}$ south of Monterey, concluding that low-frequency "oceanic white noise" within the seiche periods of 20-60 min might continuously force bay modes. The oceanic noise was hypothesized to consist of low-frequency, free infragravity waves forced by short waves, and that this noise was of the order millimeters in amplitude. So while the term "noise" applies in the context of a low amplitude background signal, and the qualifier "white" expresses a spatially uniform and wide range of temporal distributions, the underlying processes are coherent low-frequency infragravity waves. Based on a linear system transfer function between Platform Harvest and Monterey Bay water levels, he concluded that the bay amplifies this noise by factors of 16-40, resulting in coherent seiching. It was also suggested that the greatest amplification, a factor of 40 , is associated with the 27.4 min mode; however, as discussed below and in agreement with Lynch (1970), we find that this is not a bay mode but a tidally forced shelf mode, and find an amplification factor $(Q)$ of 12.9. Further, as discussed below, we find low-frequency infragravity waves may not have sufficient energy to drive the observed oscillations, but are likely a contributor to observed seiche amplitude variability.

The foregoing suggests that coastal seiche are not to be considered solely transitory phenomena, yet it seems that continuous seiching is not as widely known as its transitive cousin. For example, Bellotti et al. (2012) recognized the importance of shelf and bay modes to tsunami amplification, but considered them to be independent processes, and the comprehensive review by Rabinovich (2009) falls short of continuous seiche recognition by noting that "in harbours and bays with high $Q$ factors, seiches are observed almost continuously".

The focus of this paper is to present evidence in pursuit of the questions posed by Giese and Chapman (1993) and Breaker et al. (2010), namely, is there a continuous global excitation of seiches, and what is the source? We find that perpetual seiches are indeed present at six harbors examined around the Pacific, suggesting that there is a widely occurring excitation. Spectral analysis of water levels identifies shelf modes at each location as tidally forced standing waves in agreement with Webb (1976) and Clarke and Battisti (1981), and identifies resonances down to harbor and pier scales.

Decomposition of shelf-resonance time series into intrinsic mode functions (IMFs) allows us to examine temporal characteristics of shelf resonance in detail, leading to identification of fortnightly tidal signatures in the shelf modes. An energy assessment of the available power from the shelf modes as well as the power consumed to drive and sustain observed oscillations in Monterey Bay indicates that shelf modes are indeed energetic enough to continually drive seiches. In terms of the query posed by Giese and Chapman (1993), we will suggest that their results are specific to locations where large internal waves are known to occur, and that shelf resonances driven by tides might constitute a more general excitation of continuous bay and harbor modes.

\section{Resonance}

Let us first recall some essentials of resonance as a general phenomenon. The simple harmonic oscillator consisting of a frictionless mass $m$ coupled to a spring serves as a useful example. When the mass is displaced from equilibrium, the spring imposes a restoring force $F=k_{\mathrm{s}} x$, where $k_{\mathrm{s}}$ is the 
spring constant and $x$ the displacement. Applying the equation of motion to this expression results in a second order differential equation with solution $x(t)=A \cos \left(\omega_{0} t+\phi\right)$, where $A$ is the amplitude of the resulting oscillation, $\omega_{0}$ the frequency of oscillation, and $\phi$ a phase constant. The frequency of oscillation is $\omega_{0}=\sqrt{k_{\mathrm{s}} / m}$ and it is evident that this natural frequency is a property of the system governed by the stiffness of the spring and the mass, and is not influenced by the displacement or force which initiated the oscillation. When one adds damping to the system, or considers a different physical system such as a pendulum, vibrating string, electrical circuit, or in our case a semi-closed basin of water, the natural frequency remains a property of the system, not of the forcing.

A hallmark of resonance occurs when a resonant system is driven at or near the resonant frequency, and the resulting amplitude is maximized. This is conventionally expressed by an amplification factor of the form $\left(\omega-\omega_{\mathrm{r}}\right)^{-2}$, where $\omega_{\mathrm{r}}=\omega_{0} \sqrt{1-2 \zeta^{2}}$ is the resonant frequency of the system, $\omega$ the frequency of the driving force, and $\zeta$ the damping ratio which, in the case of a damped mass-spring system, is $\zeta=\frac{c}{2 \sqrt{k_{s} m}}$, where $c$ is an integration constant. Again, the natural or resonant frequency is a property of the system, and as demonstrated by our simple harmonic oscillator, it is not required to drive a resonant system at or near the resonant frequency in order to initiate and sustain small-amplitude resonant oscillations.

This is consistent with our hypothesis that tidally forced shelf resonances can initiate and sustain small-amplitude bay or harbor seiching even though the tidal forcing is not frequency matched to the seiche. An energy analysis below, based on the observed resonant properties of water levels in Monterey Bay, illustrates this. Since the terms mode and resonance represent the same underlying property of the system, specifically a characteristic eigenmode, we use these two terms interchangeably. We apply modifiers of shelf, bay, or harbor to qualify the spatial scale and domain over which the mode operates.

\section{Locations and data}

We examine tide gauge water levels from six bays and harbors shown in Fig. 1 with the tide gauge location denoted with a star. Monterey Bay is located on the central California coast of North America, Hawke and Poverty Bays on the eastern coast of the North Island of New Zealand, Hilo resides on the western shore of the island of Hawaii, Kahului on the northern shore of the island of Maui, and Hononlulu on the southern shore of the island of Oahu. Tides at these stations can be characterized as mixed semidiurnal with mean tidal ranges listed in Table 1.

Three of the bays (Monterey, Hawke, and Poverty) can be characterized as semi-elliptical open bays with lengthto-width ratios of $1.9,2.0$, and 1.4 , respectively. We therefore anticipate a degree of similarity between their resonance
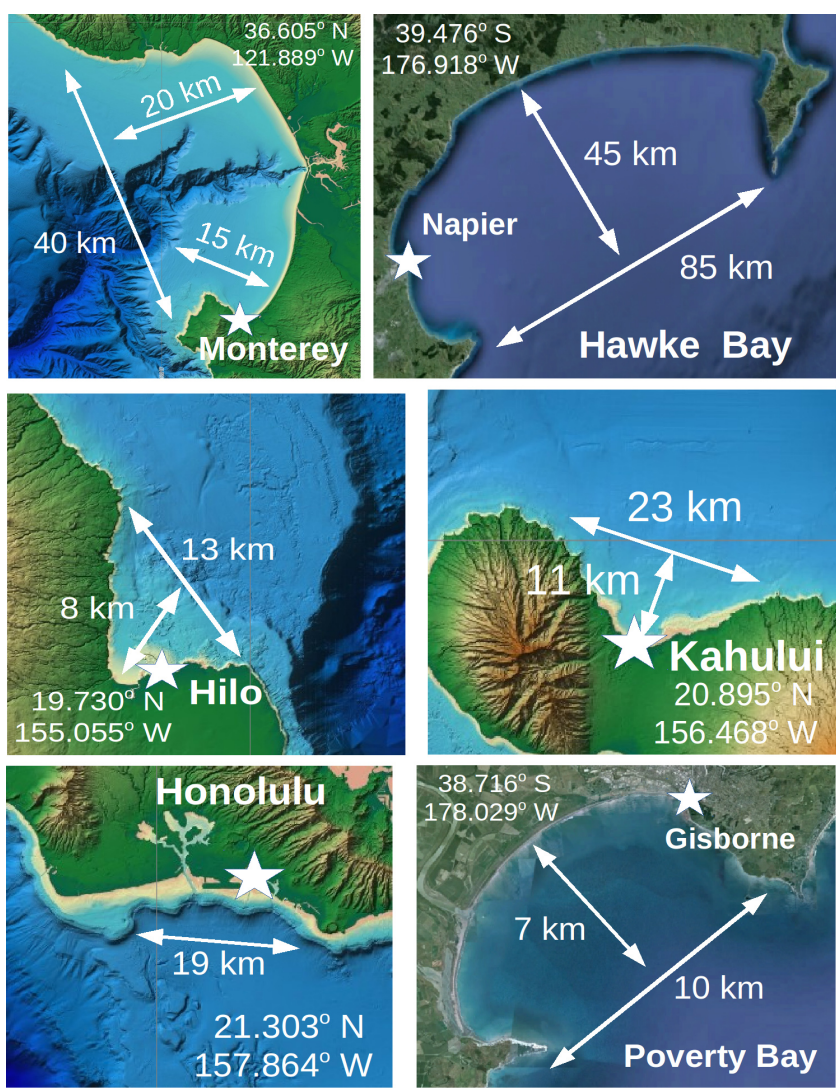

Figure 1. Location and approximate dimensions of bays. Tide gauge locations are marked with a star and denoted by latitude and longitude.

Table 1. Tidal ranges at the six tide gauges. GT is the great diurnal range (difference between mean higher high water and mean lower low water) and $\mathrm{MN}$ the mean range of tide (difference between mean high water and mean low water).

\begin{tabular}{lcc}
\hline Location & $\begin{array}{r}\text { GT } \\
(\mathrm{m})\end{array}$ & $\begin{array}{r}\text { MN } \\
(\mathrm{m})\end{array}$ \\
\hline Monterey & 1.63 & 1.08 \\
Hawke & 1.78 & 1.06 \\
Hilo & 0.73 & 0.53 \\
Kahului & 0.69 & 0.48 \\
Honolulu & 0.59 & 0.39 \\
Poverty & 1.58 & 1.06 \\
\hline
\end{tabular}

structures. Bays at Hilo and Kahului are also similar with a triangular or notched coastline, while Honolulu is an inland harbor of Mamala Bay.

Data for Hawke and Poverty bays at the Napier (NAPT) and Gisborne (GIST) tide gauges, respectively, are recorded at a sample interval of $T_{\mathrm{S}}=1 \mathrm{~min}$, and are publicly available from Land Information New Zealand (LINZ) at http://apps.linz.govt.nz/ftp/sea_level_data/. Data for Monterey and Hilo at a sample interval of $6 \mathrm{~min}$ are available 
Table 2. Approximate shelf widths and dimensions of bays and harbors, data period of record, and sampling interval $T_{\mathrm{s}}$. Note that data from Hilo and Monterey include both long-period data recorded at $T_{\mathrm{S}}=6 \mathrm{~min}$ and short-period data recorded at $T_{\mathrm{S}}=1 \mathrm{~s}$.

\begin{tabular}{|c|c|c|c|c|c|}
\hline Location & $\begin{array}{l}\text { Harbor } \\
(\mathrm{m})\end{array}$ & $\begin{array}{l}\text { Bay } \\
(\mathrm{km})\end{array}$ & $\begin{array}{l}\text { Shelf } \\
(\mathrm{km})\end{array}$ & Period of Record & $T_{\mathrm{S}}$ \\
\hline Monterey Bay and Harbor & $600 \times 500$ & $40 \times 20$ & 15 & $\begin{array}{l}25 \text { August } 1996-23 \text { June } 2014 \\
14 \text { September-29 November } 2013\end{array}$ & $\begin{array}{l}6 \min \\
1 \mathrm{~s}\end{array}$ \\
\hline Hawke Bay, Napier Harbor & $650 \times 360$ & $85 \times 45$ & 60 & 18 July 2012-9 August 2013 & $1 \mathrm{~min}$ \\
\hline Hilo Bay and Harbor & $1950 \times 1000$ & $13 \times 8$ & 17 & $\begin{array}{l}7 \text { August } 1994-15 \text { February } 2010 \\
18 \text { February-4 March } 2014\end{array}$ & $\begin{array}{l}6 \mathrm{~min} \\
1 \mathrm{~s}\end{array}$ \\
\hline Kahului Bay and Harbor & $1100 \times 950$ & $23 \times 11$ & 20 & 14 February-4 June 2013 & $1 \mathrm{~s}$ \\
\hline Mamala Bay, Honolulu Harbor & $1000 \times 500$ & $19 \times 5$ & 15 & 30 June-27 September 2012 & $1 \mathrm{~s}$ \\
\hline Poverty Bay, Gisborne Harbor & $500 \times 300$ & $10 \times 7$ & 45 & 19 April 2009-11 August 2010 & $1 \mathrm{~min}$ \\
\hline
\end{tabular}

from the National Oceanic and Atmospheric Administration (NOAA) tide gauges at http://tidesandcurrents.noaa.gov/ stations.html?type $=$ Water+Levels. In addition to these publicly available data, we also analyze water level data from independent wave studies at Honolulu, Hilo, and Monterey sampled at $1 \mathrm{~s}$ intervals. In Honolulu, data were collected by Seabird 26+ wave and water level recorders using Paroscientific Digiquartz pressure sensors at two locations, one collocated with the NOAA tide gauge inside the harbor, and the other at $157.865^{\circ} \mathrm{W}, 21.288^{\circ} \mathrm{N}$ outside Honolulu harbor. At Monterey and Hilo, data were recorded at $1 \mathrm{~s}$ intervals by WaterLog H-3611 microwave ranging sensors colocated with the NOAA tide gauges. Table 2 lists the approximate bay and harbor dimensions along with the periods of record and sampling intervals.

\section{Continuous modes}

Continuous seiching throughout a 17.8-year period has been observed, but most studies are limited to periods less than a year, one or a few coastal locations, and a single geographic region. In Fig. 2, we present water level spectrograms at six locations around the Pacific basin where vertical bands are associated with seasonal or episodic wave energy, and horizontal bands indicate the presence of persistent oscillations. These oscillations appear to have essentially invariant amplitudes over an extended period of time suggesting that timevarying processes such as weather or waves are not likely forcings. For example, inspection of the Kahului data at periods near $0.2 \mathrm{~min}(12 \mathrm{~s})$ reveals time-varying amplitudes from wind waves and swell, whereas the longer-period oscillations are essentially constant. We therefore have reason to suspect that there is a continuous forcing of bay and harbor oscillations.

A close examination of modes at Kahului with periods between 1 and $5 \mathrm{~min}$ does reveal a time-dependent frequency modulation. The 2 min mode is a good example of where a distinct sinusoidal oscillation in period is found throughout the record. This behavior is also observed at Monterey (Park et al., 2015), Hilo, and Honolulu where high-resolution
$(1 \mathrm{~Hz})$ data were available, but is not shown in Fig. 2. These modulations are coherent with the tides and are a manifestation of changing boundary conditions (water depth, exposed coastline, and spatial resonance boundaries) as water levels change with the tide. It should be noted that these modes are not directly forced by tidal energy but rather by wind waves, and that their frequency is changing due to changes in the system as the tide changes water levels.

\section{Mode identification}

Spectrograms provide information regarding time dependence of energy, but are not well suited for obtaining detailed frequency resolution. To identify resonances in the water level data, we estimate power spectral densities with smoothed periodograms (Bloomfield, 1976) as shown in Fig. 3. The Monterey and Hilo estimates are composites of $6 \mathrm{~min}$ and $1 \mathrm{~s}$ data with periods longer than $12 \mathrm{~min}$ represented by spectra of the $6 \mathrm{~min}$ data. Horizontal arrows indicate the range of modes associated with their respective spatial domains, as discussed below. Triangles mark the tidally forced shelf resonances, also discussed below.

To relate temporal modes with spatial scales, we find solutions to the general dispersion relation $\omega^{2}=g k \tanh (k d)$, where $\omega$ is the mode frequency obtained from power spectra in Fig. 3, $k$ the wavenumber, and $d$ the water depth which is a representative value from nautical charts over the horizontal dimensions of the respective mode wavelength in the bay or harbor. This provides estimates of the modal wavelength $\lambda=2 \pi / k$, which we list as $\lambda / 2$ or $\lambda / 4$ in Table 3 for all prominent modes. $\lambda / 2$ corresponds to spatial modes between two fixed boundaries, for example between two opposing coasts of a bay, as found in the longitudinal direction of the semi-elliptical bays, while $\lambda / 4$ corresponds to one fixed and one open (free) boundary condition, as found in a transverse mode where one boundary is a coast and the other the open sea, as is the case for the tidally forced shelf resonances.

For example, the $55.9 \mathrm{~min}$ mode at Monterey and the 160170 min modes at Hawke correspond to longitudinal modes between the ends of the bays and are therefore delineated 


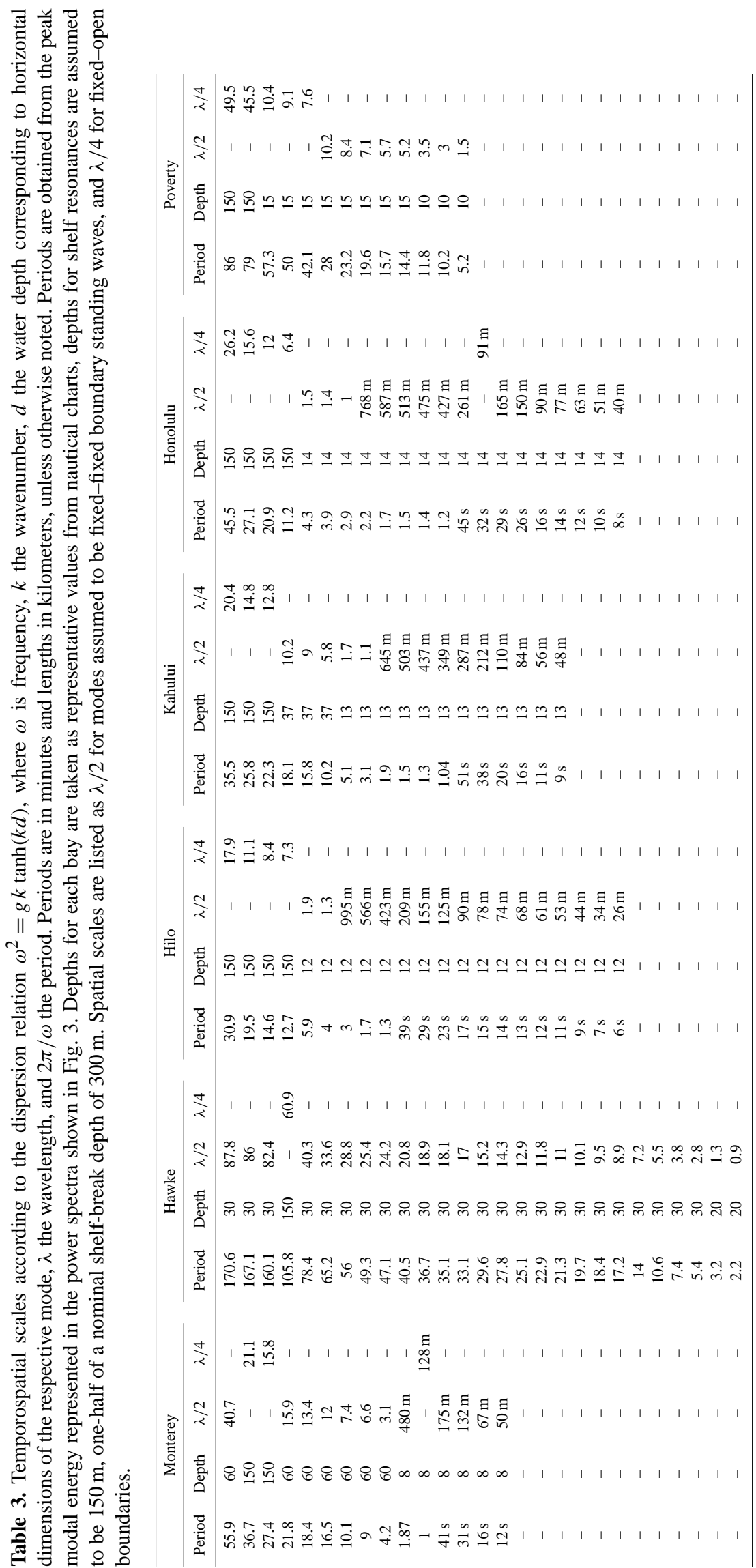



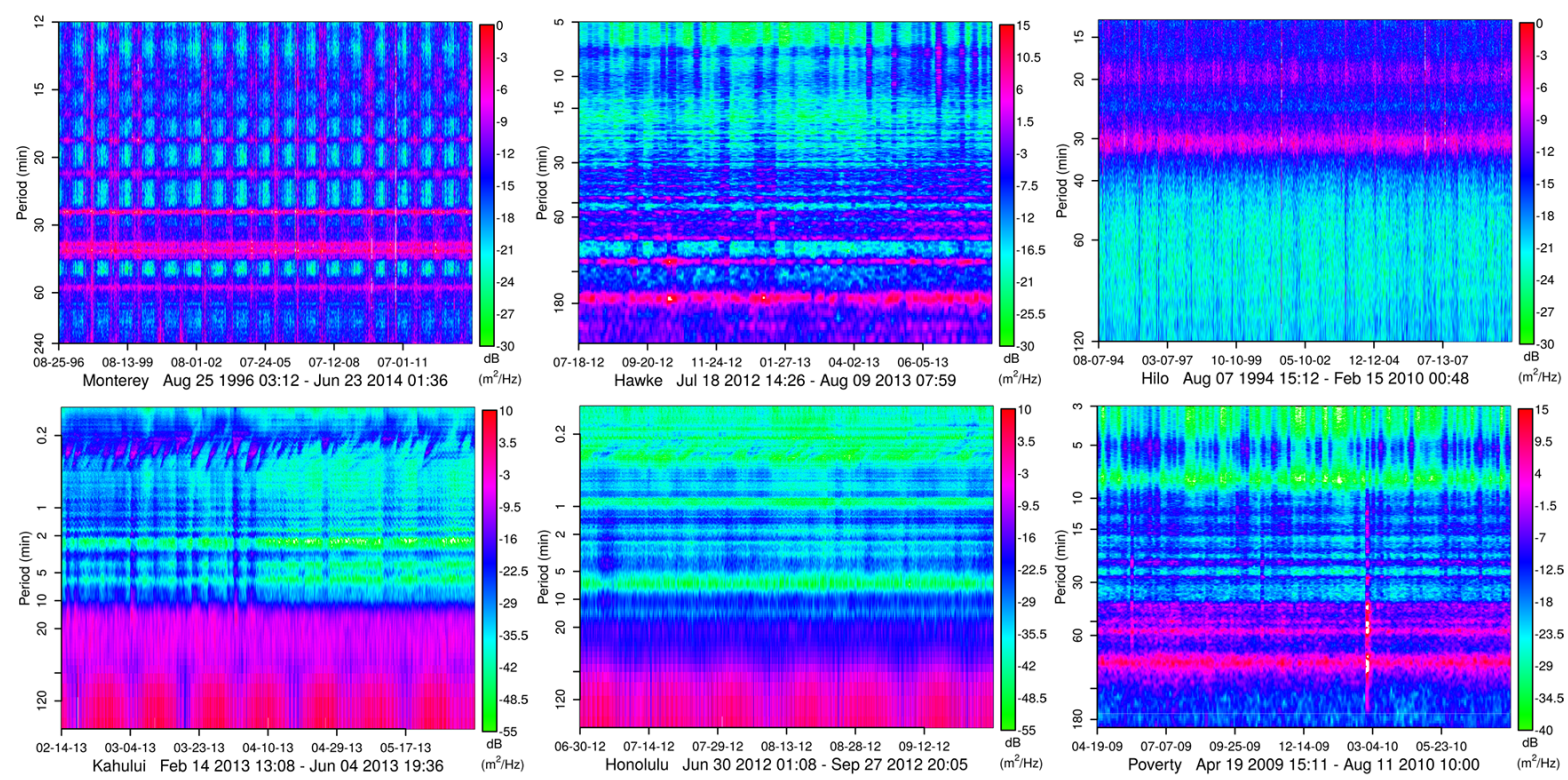

Figure 2. Spectrograms of water level data at each tide gauge. Horizontal bands indicate continuous oscillations, vertical bands are associated with periods of increased wave energy.
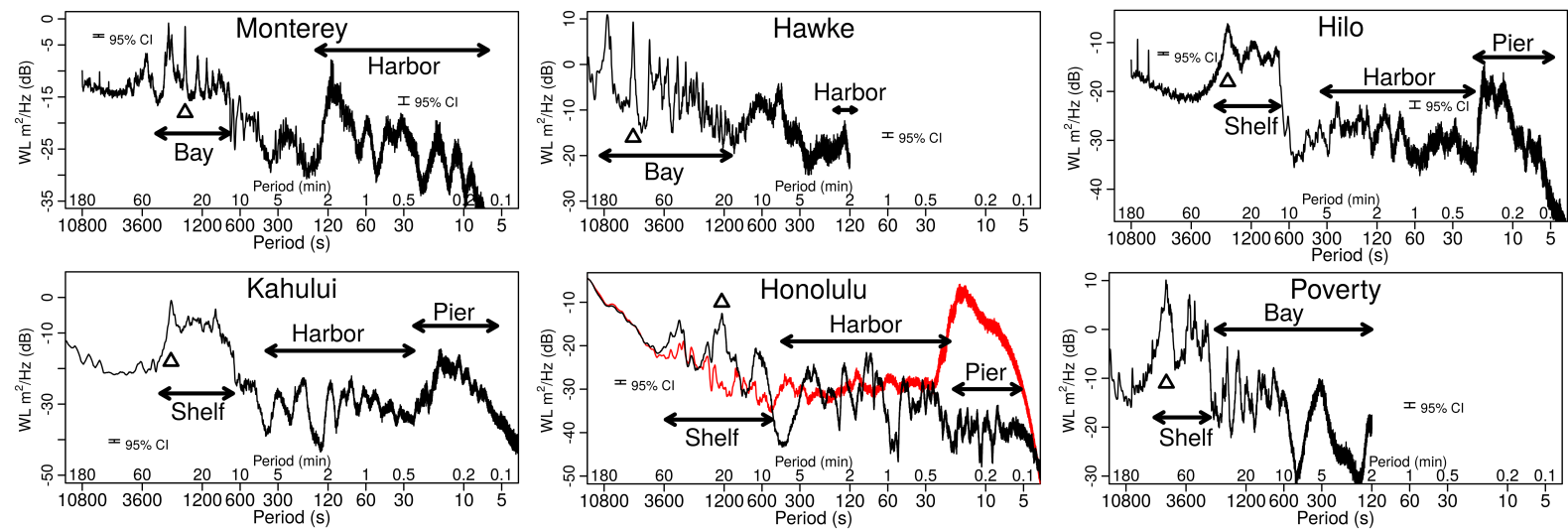

Figure 3. Power spectral density (PSD) estimates of water level (WL) at each tide gauge. Horizontal arrows indicate the frequency span of resonant modes associated with spatial scales. Triangles mark the tidally forced shelf resonance. The red curve at Honolulu plots data from outside the harbor.

as closed-boundary $\lambda / 2$ modes. The majority of the openboundary condition modes correspond to transverse bay and shelf modes, however there are exceptions, such as the $1 \mathrm{~min}$ mode at Monterey and the $32 \mathrm{~s}$ mode at Honolulu, which are open-boundary waves supported by open basins near the tide gauges, as evidenced on harbor maps. We cannot assure that all entries in Table 3 are properly attributed as $\lambda / 2$ or $\lambda / 4$ modes, as we have not closely examined the physical boundary conditions of each mode.

\subsection{Shelf resonance}

The period of a shallow water wave resonance supported by a fixed-free boundary condition is expressed in Merian's for- mula for an ideal open basin as $T=4 L / \sqrt{g d}$, where $L$ is the shelf width corresponding to $\lambda / 4$, and $d$ the basin depth (Proudman, 1953). Similarly, a shelf resonance is dynamically supported when the shelf width is approximately equal to $g \alpha /\left(\omega^{2}-f^{2}\right)$, where $g$ is the gravitational acceleration, $\alpha$ the shelf slope, $\omega$ the frequency of oscillation, and $f$ the Coriolis parameter (Clarke and Battisti, 1981). Table 4 lists solutions for shelf-mode period (inverse of frequency) for each of the bays, where the shelf slope is approximated as the depth of the shelf break divided by the shelf width, and where the basin depth is taken as one-half the shelf break depth. Also listed are modal periods deemed to represent the shelf resonances obtained from the power spectra in Fig. 3. The agreement is reasonable given the simplistic formula- 
Table 4. Estimates of shelf-resonance periods. $T_{\mathrm{R}}$ is a solution to $L=g \alpha /\left(\omega^{2}-f^{2}\right)$, where $L$ is the shelf width, $g$ the gravitational acceleration, $\alpha$ the shelf slope, $\omega$ the frequency of oscillation, and $f$ the Coriolis parameter. The shelf slope is estimated as break depth/width where we assume a break depth of $300 \mathrm{~m} . T_{\mathrm{M}}$ is from Merian's formula $T_{\mathrm{M}}=4 L / \sqrt{g d}$ for an open basin, where $d$ is the basin depth which we assume to be one-half the shelf break depth. $T_{\mathrm{PSD}}$ are values from the power spectral density estimates from shelf-mode frequencies marked with triangles in Fig. 3.

\begin{tabular}{lccccc}
\hline Location & $\begin{array}{c}\text { Latitude } \\
\left({ }^{\circ}\right)\end{array}$ & $\begin{array}{c}\text { Width } \\
(\mathrm{km})\end{array}$ & $\begin{array}{c}T_{\mathrm{R}} \\
(\mathrm{min})\end{array}$ & $\begin{array}{c}T_{\mathrm{M}} \\
(\mathrm{min})\end{array}$ & $\begin{array}{c}T_{\mathrm{PSD}} \\
(\mathrm{min})\end{array}$ \\
\hline Monterey & 36.6 & 15 & 28.9 & 26.1 & 27.4 \\
Hawke & 39.5 & 60 & 115.2 & 104.3 & 105.8 \\
Hilo & 19.7 & 17 & 32.8 & 29.5 & 30.9 \\
Kahului & 20.9 & 20 & 38.6 & 34.8 & 35.5 \\
Mamala & 21.3 & 15 & 29.0 & 26.1 & 27.1 \\
Poverty & 38.7 & 45 & 86.6 & 78.2 & 79.0 \\
\hline
\end{tabular}

tions and crude spatial representations, and, when viewed from the perspective of the apparently time-invariant modal energy evident in the spectrograms and with recognition of tidal energy as a driver of shelf resonances, suggests that tidally forced shelf resonances are continually present.

\subsection{Dynamic similarities}

Topological similarities between Monterey and Hawke bays are striking, each a semi-elliptical open bay with aspect ratios of 2.0 and 1.9 respectively, although a factor of 2 different in horizontal scale. One might expect that these similarities would lead to affine dynamical behavior in terms of modal structure, although not the specific modal resonance periods, and that indeed appears to be the case as seen in Fig. 3. Both bays exhibit highly tuned resonances evidenced by high quality factors $(Q)$ in the bay modes. The shelf resonances of both bays, $27.4 \mathrm{~min}$ at Monterey and $105.8 \mathrm{~min}$ at Hawke, indicated with the triangle symbol in each plot, are exceptional examples of this, while the longer period modes $(56 \mathrm{~min}$ at Monterey and $165 \mathrm{~min}$ at Hawke) correspond to longitudinal bay oscillations. The semi-elliptical topology of these bays is such that boundaries of the longitudinal modes are not parallel as in an ideal rectangular basin, but are crudely represented as semi-circular boundaries. The range of spatial scales between these boundaries is reflected in the longitudinal spectral peaks, with broad frequency spans at the base and evidence of a series of closely spaced modes corresponding to a range of wavelengths. This is contrasted to the shelf modes where the resonances are remarkably narrow, indicating the narrow range of spatial scales reflected in the relatively uniform widths of the shelves at Hawke and Monterey Bays.

Poverty Bay is the other semi-elliptical open bay and exhibits the same generic modal structure, although the bay modes here are shorter in period due to the significantly smaller size, and the shelf mode is the longest period mode. It is also evident here that the shelf mode is mixed with other modes, as it does not have a high $Q$ factor as found at Monterey and Hawke, although part of this difference could result from poorer trapping, more radiation, or other energy loss associated with this mode.

Hilo and Kahului bays also share structural similarity, but lack the high degree of topological symmetry found in the semi-elliptical bays that support both longitudinal and transverse modes. As is the case for the semi-elliptical bays, the power spectra of these two bays are conspicuously similar, with the substantial difference being the precise frequencies of their associated modes. Here, shelf modes appear to dominate the water level variance at periods less than one hour, but rather than a set of discrete, high- $Q$ shelf resonances as found at Monterey and Hawke, they are energetic over a broad range of frequencies and spatial scales. This suggests that the shelves here are not well represented by a uniform width, but encompass a range of scales to the shelf break, as evidenced in bathymetric data. In the following sections we examine specific resonance features at each of the bays.

\subsection{Monterey}

Monterey Bay seiching has been studied since at least the 1940s (Forston et al., 1949) with a comprehensive review provided by Breaker et al. (2010). The primary bay modes at the Monterey tide gauge have periods of 55.9, 36.7, 27.4, $21.8,18.4$, and $16.5 \mathrm{~min}$, where the 55.9 min mode represents the fundamental longitudinal mode, while the $36.7 \mathrm{~min}$ harmonic is attributed to the primary transverse mode. We identify the 27.4 min mode as a shelf resonance, also recognized by Lynch (1970), and consider it to be a potential continuous forcing of water level oscillations throughout the bay at periods longer than $10 \mathrm{~min}$. The harbor modes (Fig. 3) have been associated with resonances between breakwaters, and are amplified by wave energy, whereas the bay modes are weakly dependent on wave forcing (Park et al., 2015).

\subsection{Hawke}

Hawke Bay is approximately $85 \mathrm{~km}$ long and $45 \mathrm{~km}$ wide with a rich set of modes at periods between 20 and $180 \mathrm{~min}$. Modes at periods of 170.6, 167.1, and 160.1 min correspond to longitudinal oscillations, while the $105.8 \mathrm{~min}$ oscillation is identified as a shelf resonance (Table 3 ).

\subsection{Hilo}

At Hilo we are afforded full spectral frequency coverage and find that pier modes have periods below 20 s corresponding to spatial scales less than $100 \mathrm{~m}$. These modes are excited by waves and swell just as the harbor modes at Monterey. Harbor modes at periods of 3, 4, and 5.9 min correspond to standing waves within the breakwater and spatial scales of 1 , 
1.3 , and $1.9 \mathrm{~km}$, respectively. The shelf offshore Hilo is not a uniform width, but transitions from less than $2 \mathrm{~km}$ just south of the bay to roughly $18 \mathrm{~km}$ along the northern edge, with the spectra revealing a corresponding plateau at periods between 10 and $30 \mathrm{~min}$, with a rather broad shelf resonance centered on a period of $30.9 \mathrm{~min}$, qualitatively different from the high$Q$ shelf resonances at Monterey and Hawke bays. This wellknown 30.9 min mode at Hilo corresponds to a shelf resonance on a shelf width of approximately $17 \mathrm{~km}$.

\subsection{Kahului}

Oscillations at Kahului follow the same general structure as Hilo with wave and swell excited pier modes at periods less than $20 \mathrm{~s}$, and within-harbor pier-breakwater modes at periods of 51 and $63 \mathrm{~s}$. The primary harbor mode has peak energy at 188 seconds $(3.1 \mathrm{~min})$ corresponding to a $\lambda / 2$ spatial scale of $1.1 \mathrm{~km}$, which is the dominant lateral dimension of the harbor.

An interesting feature of the Kahului power spectra is a low energy notch between periods of 120 and 160 s. This lack of energy corresponds to a lack of standing wave reflective boundaries at scales of $\lambda / 2$ from 650 to $1000 \mathrm{~m}$. Such low energy features are present in all spectra indicating spatial scales where standing waves are not supported. The dominant shelf mode at Kahului has a period of $35.5 \mathrm{~min}$, similar to that of Hilo.

\subsection{Honolulu}

At Honolulu we have the benefit of both short sample times $\left(T_{\mathrm{S}}=1 \mathrm{~s}\right)$ and two gauge locations, one inside the harbor and one on the reef outside the harbor. The offshore power spectrum is shown in red in Fig. 3 exemplifying an open ocean or coastal location dominated by wind waves and swell. The rejection of wind wave energy inside the harbor is impressive, revealing a set of pier modes in the 8-20 s band supported by rectangular basins around the gauge. Modes with periods of 82 and $88 \mathrm{~s}$ correspond to waves with $\lambda / 2$ of approximately $500 \mathrm{~m}$, which is the fundamental dimension of the basin.

While the harbor is quite efficient in rejection of wind waves and swell, amplification of the shelf mode and other long period resonances is a striking manifestation of the "harbor paradox" as noted by Miles and Munk (1961). Indeed, power spectra of the other harbors in Fig. 3 might suggest that they may be even more efficient amplifiers.

\subsection{Poverty}

Poverty Bay is a small-scale version of Hawke and Monterey bays with a similar resonance structure. However, the bay is small enough that the lowest frequency mode is not a longitudinal mode within the bay, but is the shelf resonance at a period of $79 \mathrm{~min}$. The $57.3 \mathrm{~min}$ mode is not explicitly a Poverty Bay mode, but is a longitudinal mode of the open bay between Table Cape to the south and Gable End to the
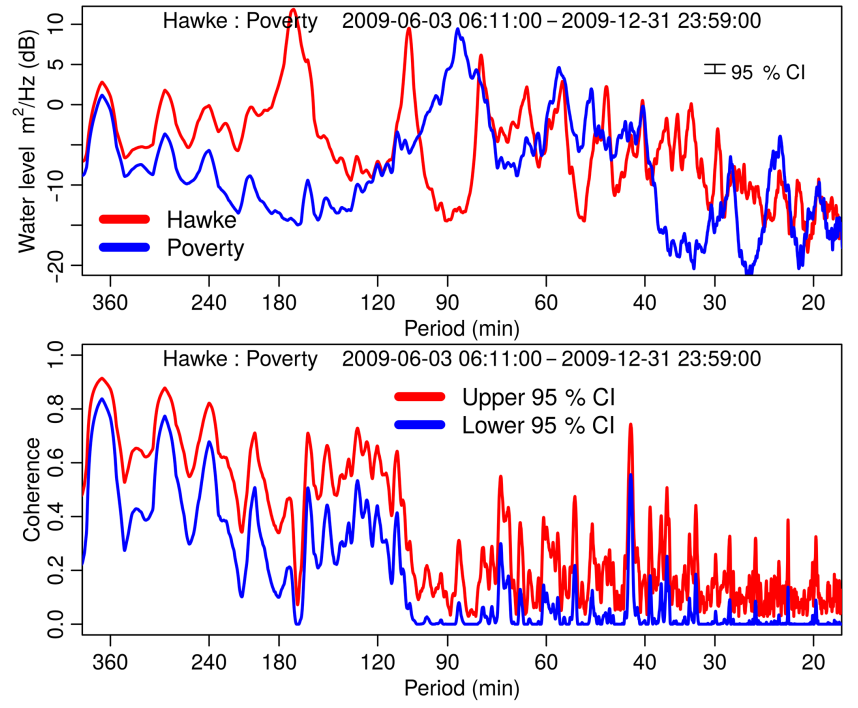

Figure 4. Power spectral density (top) of concurrent water levels at Napier in Hawke Bay, and Gisborne in Poverty Bay. Bottom: coherence of the power spectra shown as the upper and lower $95 \%$ confidence interval values.

north, inside which Poverty Bay is inset. We also note that the 42.1 min mode is a shelf edge wave evident in both Hawke and Poverty bays as discussed below. The reader is referred to Bellotti et al. (2012) for a detailed numerical evaluation of Poverty Bay shelf and bay modes.

\subsection{Hawke and Poverty}

Hawke and Poverty bays are located approximately $35 \mathrm{~km}$ apart along the southeast coast of northern New Zealand. Concurrent 7-month records allow examination of crossspectral statistics between the two locations, with power spectra presented in the upper panel of Fig. 4 and coherence in the lower panel plotted as the upper and lower $95 \%$ confidence intervals. Power spectra reveal that the two bays share shallow water tidal forcings at periods longer than $180 \mathrm{~min}$, but are essentially independent in terms of major oscillation frequencies between 20 and $180 \mathrm{~min}$. There are coincident spectral peaks near periods of 42 and $58 \mathrm{~min}$; however, the coherence of the 58 min energy is low, indicating that oscillations near periods of $58 \mathrm{~min}$ are likely independent between the two bays.

Coherence at the shallow water tidal periods $(373,288$, 240, $199 \mathrm{~min}$ ) is quite high and, as expected, has near zero phase shift (not shown). Shelf modes with periods from 100 to $160 \mathrm{~min}$ also share coherence in the 0.5 range, which is sensible since they have quarter wavelengths that are as long or longer than the $35 \mathrm{~km}$ separation distance. The only other energy with coherence reliably above the 0.5 range is the 42 minute mode. This mode has a phase shift of $-160^{\circ}$ from Napier (Hawke Bay) to Gisborne (Poverty Bay), indicating a traveling wave moving from south to north along the coast, 
empirically validating the shelf edge-wave explanation inferred numerically by Bellotti et al. (2012).

\section{Shelf metamodes}

Since tidally forced shelf modes are a plausible driver of seiches, we expect that tidal amplitude variance should be reflected in seiche amplitudes, a view consistent with the strong fortnightly modulation of seiche amplitude reported by Giese et al. (1990) and Wijeratne et al. (2010). To examine such a dependence, Fig. 5 plots time series of shelf-mode amplitude at each station. Amplitudes are power-spectral estimates of the water level oscillation measured at the tide gauge at the frequency of the corresponding shelf mode for each station. To examine the mean temporal behavior of shelf modes we decompose the time series into intrinsic mode functions (IMFs) by empirical mode decomposition (EMD, Huang and $\mathrm{Wu}, 2008)$. The temporal low-pass response of the shelf modes is shown in Fig. 5 by the thick lines which are a superposition of the lowest frequency intrinsic mode functions (IMFs). We term these IMFs of shelf-mode amplitudes as metamodes.

It is clear from Fig. 5 that shelf modes are continually present at all stations, albeit with significant temporal variability. The metamodes reveal annual modulations in the long period records of Monterey and Hilo, and fortnightly cycles at Kahului and Honolulu.

To assess the relative contribution of individual shelfmode IMFs (metamodes) to the total shelf-mode variance, we list the mean period in days $(T)$ of each metamode Hilbert instantaneous frequency vector, and the estimated partial variance of each metamode IMF with respect to the total variance in Table 5. The partial variance is determined by excluding, one-by-one, IMFs from the reconstructed signal (sum of all IMFs) and comparing that result to the variance of the original signal. Since IMFs are not required to be linear or mathematically orthogonal, the sum of partial variances is not restricted to a value of 1 , although in practice IMFs are nearly orthogonal and the sum of these partial variances is within several percent of unity.

We note that the fortnightly astronomical tidal constituents, the lunisolar synodic fortnightly $\left(M_{\mathrm{sf}}\right)$ and lunisolar fortnightly $\left(M_{\mathrm{f}}\right)$, have periods of 14.76 and 13.66 days, respectively, with IMFs closest to these periods highlighted in Table 5 and shown in Fig. 6. Here, we find that the fortnightly variance in shelf-mode amplitude at Monterey and Hilo is the dominant contribution, while at Kahului, Hawke and Poverty bays it is the second strongest metamode. At Honolulu and Kahului the bulk of the metamode variance is on sub-daily timescales, however, the fortnightly mode is the strongest of the modes at diurnal and longer scales, a relation that holds at all stations except Poverty Bay. We also note, in Fig. 6, evidence of a seasonal dependence in metamode amplitude, and will correlate these IMFs with their corresponding fortnightly tidal IMFs below.
The foregoing indicates that fortnightly metamodes are present at all six stations, suggesting that tidal forcing of shelf modes is a likely driver. To assess an assumed linear dependence between fortnightly tidal forcing and metamodes, we compute IMFs on the tidal water level data and crosscorrelate the resulting fortnightly tidal IMFs with the fortnightly metamodes. Correlations are computed over a sliding window of 20 days, with results shown in Fig. 7, where dashed red lines indicate the $95 \%$ significance threshold. An interesting feature is that while all stations exhibit near perfect correlation at times, they also episodically transition to near zero or statistically insignificant correlation. This suggests that the fortnightly modulation of tidally driven shelf resonances is also influenced by other factors, of which internal tide variability has previously been noted by Giese et al. (1990) and Wijeratne et al. (2010).

While there is significant temporal variability in the fortnightly tidal metamode correlations, it appears that the majority of the time correlations are quite high and significant above the $95 \%$ level. The IMF mode numbers and mean correlations statistics are listed in Table 6 , where $T_{\mathrm{R}} \%$ is the percentage of time that the $95 \%$ significance threshold is exceeded, $\bar{R}$ is the mean correlation of values above the $95 \%$ significance threshold, and $\overline{\mathrm{Lag}}$ the mean lag value of $95 \%$ significant correlations. Overall, these data suggest that correlations significant above the $95 \%$ level are present $76-87 \%$ of the time, and from a linear model perspective, that fortnightly tidal oscillations account for $35-50 \%$ of the metamode variance.

\section{Mode energy}

Knowledge of a mode's temporospatial characteristics allows estimation of the total energy sustained by the mode. Figure 3 indicates that Hilo, Kahului, Honolulu and Poverty bays are dominated by energy of the shelf mode, while at Hawke and Monterey bays the shelf mode is the second largest amplitude. We are therefore motivated to investigate modal energy in Monterey Bay to test our hypothesis that the tidally forced shelf resonance is a potential driver of bay oscillations from a kinematic perspective.

We estimate the total potential energy to support a mode by assuming a raised-cosine profile of amplitude $h$, either orthogonal to the shore for the transverse modes or parallel for the longitudinal modes. Multiplying this profile area $\left(A_{\mathrm{M}}\right)$ by the alongshore extent of the mode $\left(L_{\mathrm{A}}\right)$ gives the volume of water displaced: $V_{\mathrm{M}}=L_{\mathrm{A}} A_{\mathrm{M}}$, where we have neglected the influence of shoaling on the transverse modes as the wavelength is much longer than the shelf width. (This assumption is supported by the agreement between the shelf-mode spatial scales based on the observed shallow-water frequencies in Table 4.) The energy to move this volume is equivalent to the work performed to change the potential energy of the mass in the gravitational field $E_{\mathrm{M}}=\rho V_{\mathrm{M}} h_{\mathrm{M}} g$, at an average power output of $P_{\text {out }}=E_{\mathrm{M}} / T$, where $T$ is the modal 

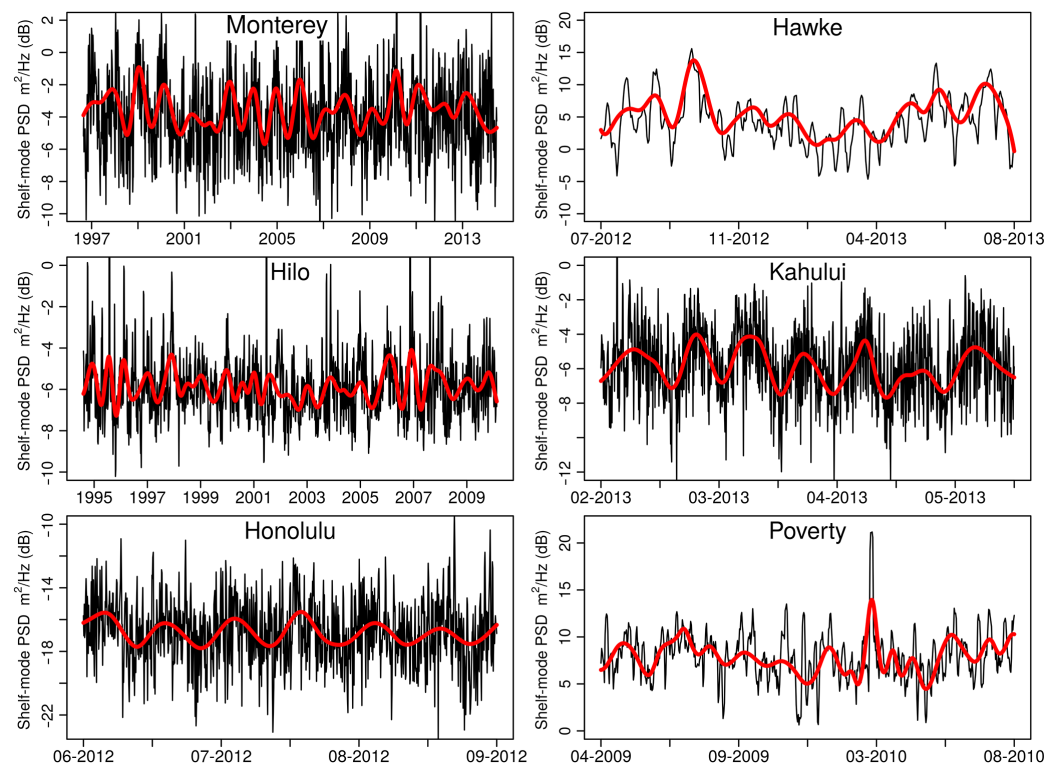

Figure 5. Shelf-resonance power spectral density (PSD) amplitudes (black) with low-frequency IMFs (metamodes) in red. The large amplitude in Poverty Bay is a result of the 27 February 2010 Chile $8.8 M$ earthquake and tsunami.

Table 5. Mean period in days $(T)$ of Hilbert instantaneous frequencies and percent variance of shelf-resonance power spectral density IMFs (metamodes). Modes with mean periods close to fortnightly tidal constituents with periods of $14.76\left(M_{\mathrm{sf}}\right)$ and 13.66 days $\left(M_{\mathrm{f}}\right)$ are highlighted in bold.

\begin{tabular}{|c|c|c|c|c|c|c|c|c|c|c|c|c|}
\hline \multirow[t]{2}{*}{ IMF } & \multicolumn{2}{|c|}{ Monterey } & \multicolumn{2}{|c|}{ Hawke } & \multicolumn{2}{|c|}{ Hilo } & \multicolumn{2}{|c|}{ Kahului } & \multicolumn{2}{|c|}{ Honolulu } & \multicolumn{2}{|c|}{ Poverty } \\
\hline & $T$ & $\%$ Var & $T$ & $\%$ Var & $T$ & $\%$ Var & $T$ & $\%$ Var & $T$ & $\%$ Var & $T$ & $\%$ Var \\
\hline 1 & 14.70 & 33.5 & 3.34 & 2.0 & 14.47 & 35.2 & 0.30 & 42.6 & 0.29 & 40.2 & 2.42 & 6.2 \\
\hline 2 & 28.31 & 22.2 & 6.27 & 5.1 & 29.99 & 22.3 & 0.60 & 17.7 & 0.51 & 19.5 & 5.52 & 19.6 \\
\hline 3 & 55.48 & 15.1 & 9.02 & 5.9 & 60.83 & 14.6 & 1.26 & 14.2 & 0.98 & 18.5 & 8.46 & 13.7 \\
\hline 4 & 105.06 & 8.1 & 13.48 & 13.9 & 137.37 & 18.2 & 2.41 & 5.3 & 1.77 & 4.7 & 14.21 & 17.9 \\
\hline 5 & 219.06 & 10.0 & 17.01 & 4.4 & 273.70 & 11.4 & 4.65 & 2.3 & 3.48 & 6.2 & 22.60 & 10.9 \\
\hline 6 & 387.16 & 8.4 & 24.48 & 7.4 & 476.62 & 0.8 & 14.58 & 18.1 & 6.07 & 3.6 & 34.31 & 8.4 \\
\hline 7 & 726.21 & 1.8 & 35.73 & 6.8 & 938.04 & 0.5 & 28.41 & 4.5 & 13.86 & 7.0 & 53.76 & 11.4 \\
\hline 8 & 1662.14 & 1.3 & 45.45 & 4.8 & 1790.81 & 0.2 & 56.98 & 2.2 & 22.55 & 0.1 & 68.84 & 7.1 \\
\hline 9 & 2244.04 & 0.2 & 65.67 & 9.7 & 4009.13 & 1.4 & - & - & 46.91 & 0.8 & 111.13 & 4.3 \\
\hline 10 & - & - & 162.08 & 35.9 & - & - & - & - & - & - & 164.22 & 5.6 \\
\hline
\end{tabular}

Table 6. Cross-correlation of fortnightly tide and shelf-resonance metamode IMFs. $T_{\mathrm{R}} \%$ is the percentage of time that the $95 \%$ confidence level is exceeded, $\bar{R}$ the mean value of $95 \%$ significant correlation over the record, and $\overline{\mathrm{Lag}}$ the mean lag value of $95 \%$ significant correlation over the record.

\begin{tabular}{|c|c|c|c|c|c|c|}
\hline \multirow[t]{2}{*}{ Location } & Tide & Shelf & $T_{\mathrm{R}} \%$ & $\bar{R}$ & $\bar{R}^{2}$ & $\overline{\mathrm{Lag}}$ days \\
\hline & \multicolumn{2}{|c|}{ IMF } & \multicolumn{4}{|c|}{$>95 \%$} \\
\hline Monterey & 5 & 1 & 87 & 0.67 & 0.45 & -0.35 \\
\hline Hawke & 7 & 4 & 84 & 0.71 & 0.50 & -0.26 \\
\hline Hilo & 5 & 1 & 82 & 0.71 & 0.50 & 0.53 \\
\hline Kahului & 7 & 6 & 86 & 0.59 & 0.35 & 0.01 \\
\hline Honolulu & 7 & 7 & 76 & 0.65 & 0.42 & 0.64 \\
\hline Poverty & 6 & 4 & 82 & 0.69 & 0.48 & -0.17 \\
\hline
\end{tabular}

period. This leading-order value does not incorporate dissipation and momentum, terms that we ignore in subsequent energy estimates.

The ratio of energy stored in the mode resonance to energy supplied driving the resonance is the $Q$ factor. If $Q$ is large (the resonance signal-to-noise ratio is high, as is the case for the shelf mode at Monterey), it may be estimated from the power spectrum: $Q=f_{\mathrm{M}} / \Delta f$, where $f_{\mathrm{M}}$ is the mode resonant frequency and $\Delta f$ the $-3 \mathrm{~dB}$ (half power) bandwidth of the mode. This allows one to estimate the power required to drive the mode $P_{\text {in }}=E_{\mathrm{M}} /(Q T)=P_{\text {out }} / Q$.

Modal length scales $(\lambda)$ are taken from Table 3, amplitudes $(h)$ are from bandpass filtering the 17.8-year water level record at the NOAA tide gauge, and $Q$ from $1 \mathrm{~Hz}$ water level power spectra $(95 \%$ CI $2.6 \mathrm{~dB}$ ) modal means over $120 \mathrm{~h}$ win- 

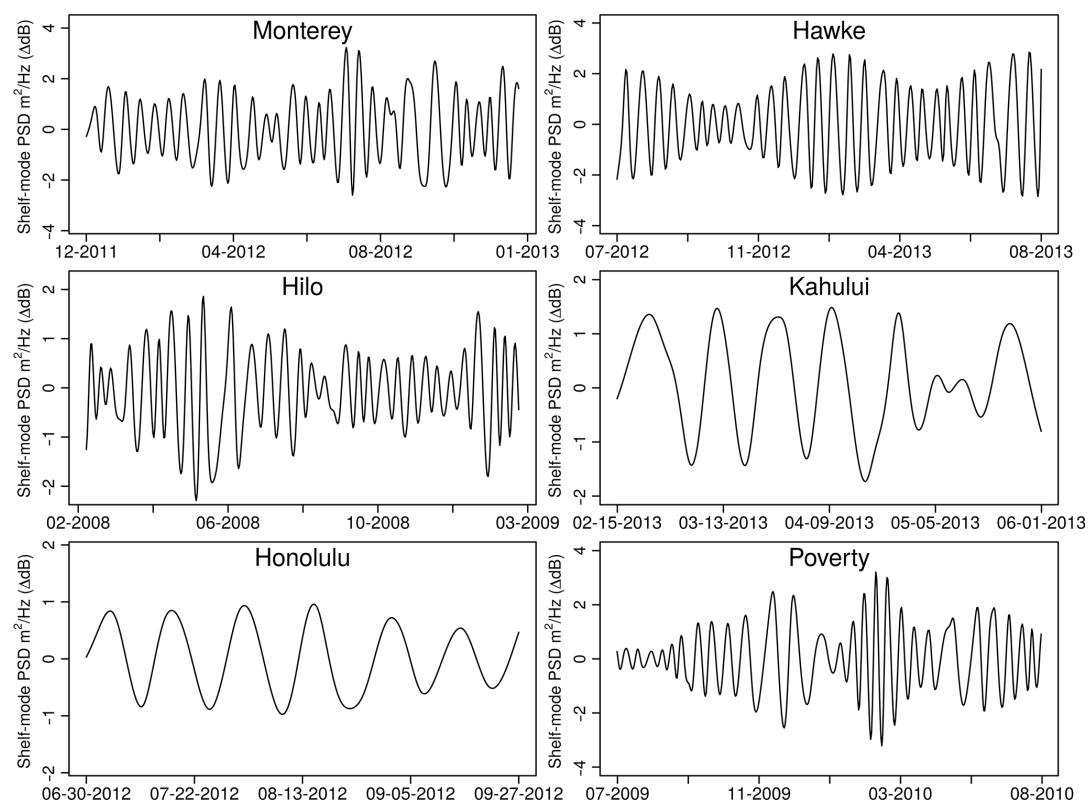

Figure 6. Intrinsic mode functions (IMF) of shelf-mode amplitude variance (metamodes) with mean Hilbert instantaneous frequencies corresponding to fortnightly periods (highlighted in Table 5). Amplitudes are with respect to the mean values shown in Fig. 5. Records at Honolulu and Kahului are limited to 3 months, while the other stations show excerpts of approximately 13 months.
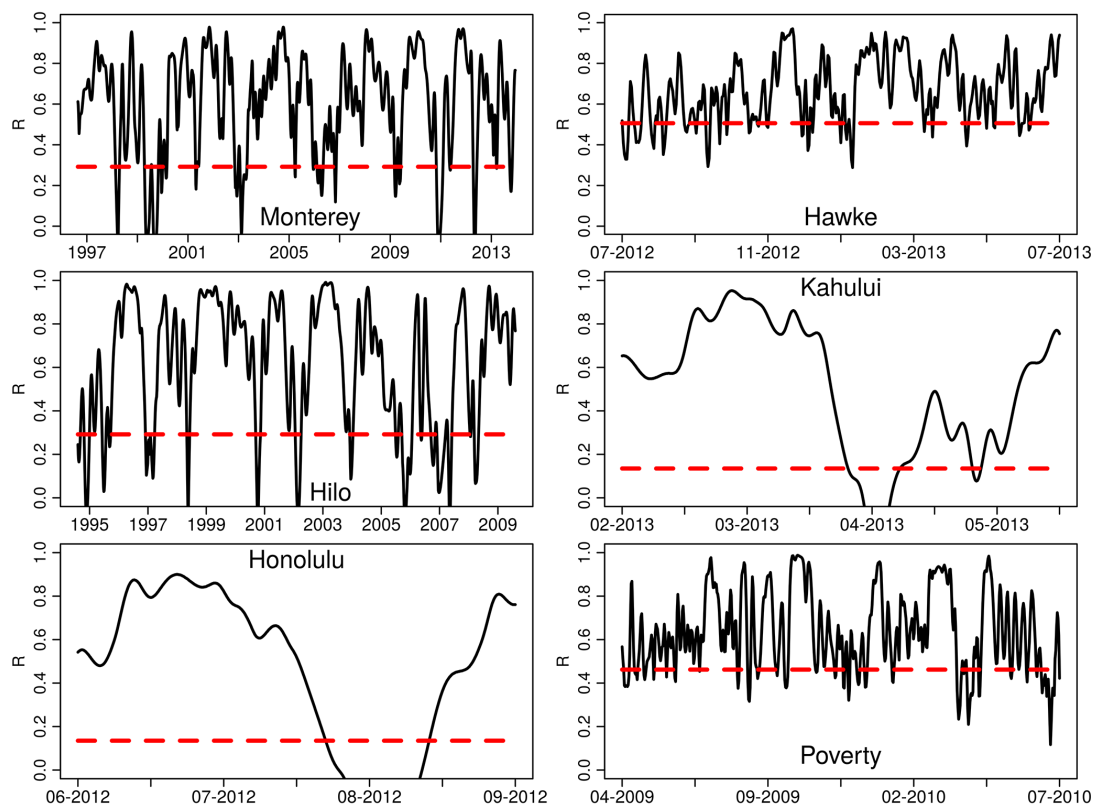

Figure 7. Correlation coefficients between tide and shelf-resonance metamode IMFs with fortnightly periods. The dashed red lines indicate the $95 \%$ confidence levels.

dows over 63 days (Park et al., 2015). The alongshore extent of the modes, $L_{\mathrm{A}}$, is estimated from a regional ocean modeling system (ROMS) implementation in Monterey Bay (Shchepetkin and McWilliams, 2005) as reported in Breaker et al. (2010).
Results of these estimates are shown in Table 7, where we find seiche amplitudes averaged over the 17.8-year period of $0.9,1.4$, and $1.6 \mathrm{~cm}$ for the 55.9, 27.4, and 36.7 min modes, respectively, although amplitudes of $4 \mathrm{~cm}$ in the $27.4 \mathrm{~min}$ mode are common during seasonal maximums. The $27.4 \mathrm{~min}$ shelf mode is estimated to produce a total power of $998 \mathrm{~kW}$, 
Table 7. Estimates of total energy and power generated by resonances in Monterey Bay. Modal amplitudes $(h)$ are mean values from bandpass filtering the 17.8 -year record of water levels at the NOAA tide gauge. $T$ is the mode period, $W_{\mathrm{FIR}}$ is the filter bandpass, $\lambda / 2$ the mode half wavelength, $L_{\mathrm{A}}$ the alongshore extent of the mode in the bay, $V$ the volume of water displaced, $E_{\mathrm{M}}$ the potential energy, $Q$ the mode amplification, $P_{\text {in }}=E_{\mathrm{M}} /(Q T)$ the input driving power of the mode, and $P_{\text {out }}=E_{\mathrm{M}} / T$ the modal power.

\begin{tabular}{cccccccccc}
\hline $\begin{array}{c}T \\
(\mathrm{~min})\end{array}$ & $\begin{array}{c}W_{\mathrm{FIR}} \\
(\mathrm{min})\end{array}$ & $\begin{array}{c}h \\
(\mathrm{~cm})\end{array}$ & $\begin{array}{c}\lambda / 2 \\
(\mathrm{~km})\end{array}$ & $\begin{array}{c}L_{\mathrm{A}} \\
(\mathrm{km})\end{array}$ & $\begin{array}{c}V \\
\left(\mathrm{Mm}^{3}\right)\end{array}$ & $\begin{array}{c}E_{\mathrm{M}} \\
(\mathrm{GJ})\end{array}$ & $Q$ & $\begin{array}{c}P_{\text {in }} \\
(\mathrm{kW})\end{array}$ & $\begin{array}{c}P_{\text {out }} \\
(\mathrm{kW})\end{array}$ \\
\hline 27.4 & $25-30$ & 1.4 & 31.6 & 38 & 33.30 & 1.64 & 12.9 & 77.6 & 998.1 \\
36.7 & $35-39$ & 1.6 & 42.2 & 40 & 52.55 & 2.91 & 7.8 & 168.6 & 1319.7 \\
55.9 & $53-59$ & 0.9 & 40.7 & 18 & 13.27 & 0.43 & 5.6 & 22.7 & 127.3 \\
\hline
\end{tabular}

which is more than sufficient to supply the required input power of both the primary longitudinal $\left(55.9 \mathrm{~min}, P_{\text {in }}=\right.$ $23 \mathrm{~kW})$ and transverse $\left(36.7 \mathrm{~min}, P_{\text {in }}=169 \mathrm{~kW}\right)$ bay modes. So even though the primary longitudinal bay modes in both Monterey and Hawke bays have larger amplitudes than the respective shelf modes, the shelf mode in Monterey supplies a continuous source of energy capable of sustaining the fundamental bay modes, which by virtue of their resonant amplification can exceed the amplitude of the shelf resonance itself. Regarding the low-frequency infragravity waves of millimeter amplitude suggested by MacMahan (2015), we note that a 27.4 min mode with an amplitude of $3 \mathrm{~mm}$ would produce an estimated $P_{\text {out }}$ of $41.6 \mathrm{~kW}$ (not shown in Table 7), which would be insufficient to drive the observed $27.4 \mathrm{~min}$ mode as it requires a power of $P_{\text {in }}=77 \mathrm{~kW}$.

\section{Discussion}

Resonant modes are a fundamental physical characteristic of bounded physical systems expressed in bodies of water as seiches. As such, they can be excited to large amplitudes by transitory phenomena such as weather and tsunamis, and since large amplitude seiches are easily observable, seiches are often viewed as transitory given that they dissipate after cessation of the driving force. Moving from transient to persistent behavior, seasonal weather patterns are known to sustain nearly continuous seiching for extended periods (Woodworth et al., 2005; Wijeratne et al., 2010), as internal waves are also known to do (Giese et al., 1990). On the other hand, small amplitude, temporally continuous seiches were recognized by Cartwright and Young (1974) and Golmen et al. (1994), with Giese and Chapman (1993) and Breaker et al. (2010) posing questions as to the possibility of global excitations. Motivated by these questions, we have examined tide gauge water levels around the Pacific basin, looking for continuous seiching and forcings.

In the process of analyzing the resonant structure of these bays and harbors, we have quantified resonant periods and estimated spatial scales corresponding to each mode (Table 3). In some cases, we have identified the physical attributes of a bay or harbor associated with specific temporospatial resonances. In a more general sense, we have also illustrated broad dynamical similarities between bays with affine topologies, such as the clearly defined modes of the semi-elliptical bays when compared to the less structured, shelf-dominated bays such as Hilo and Kahului. This analysis also provides empirical verification of the numerically inferred edge wave by Bellotti et al. (2012) near a period of 42 min along Hawke and Poverty bays.

Simple geometric and dynamical estimates of tidally forced shelf modes are consistent with modes observed in the power spectra at all stations, and their continual presence in water level spectrograms and mode amplitude time series indicates that tidally forced shelf modes are continuously present at each location. Decomposition of shelf-mode amplitude time series identifies metamodes reflecting dynamic behavior of the shelf modes, and we find that fortnightly metamodes are the dominant mode at periods longer than diurnal. Assuming that these fortnightly modulations are of tidal origin, cross-correlation of fortnightly IMFs of tidal data with the fortnightly metamodes leads to the conclusion that within the bounds of a linear system model from one-third to one-half of the fortnightly metamode variance is coherent with tidal forcing. We therefore suspect that tidally forced shelf modes are a continuous energy source in harbors and bays adjacent to continental or island shelves.

However, it is also clear that we do not understand the cyclic nature of fortnightly tidal and metamode correlation. One possibility is that there is a time-varying phase lag between the two such that destructive superposition episodically creates nulls. A linear spectral analysis might use a coherency statistic to identify this, but such an option is not available for IMFs with variable instantaneous frequencies. It is evident that internal tides play a role, and it may be that episodic changes in stratification as noted by Giese et al. (1990) lead to modulation of the metamodes and contribute to the observed decorrelation, and it is deemed likely that the free, long-frequency infragravity waves suggested by MacMahan (2015) also contribute.

A natural question is: does the proposed source contain sufficient energy to sustain the observed resonant oscillation? Power estimates of the most energetic modes at Monterey suggest that the shelf mode is fully capable as a primary driver of continuous seiche, while the low-frequency infra- 
gravity waves suggested by MacMahan (2015) may not have sufficient energy.

\section{Conclusions}

Examination of six coastal locations around the Pacific with diverse shelf conditions finds that tidally forced shelf resonances are continually present. An energy assessment of the shelf mode and primary seiche in Monterey Bay indicates that the shelf resonance is fully capable of supplying the power input required to drive the primary bay oscillations, even though the grave mode produces more output power than the shelf mode, a consequence of the resonance structure of the bay. Hawke Bay is dynamically similar to Monterey and we suspect that a similar relation holds there, while at the other locations the shelf mode is the dominant energy source. Our conclusion is that tidally forced shelf modes constitute a global candidate for continuous seiche excitation, a view consistent with that of Lynch (1970), Golmen et al. (1994), and Wijeratne et al. (2010), who identified tidally forced shelf resonances as specific seiche modes. In locations where tidally forced shelf resonance is a primary seiche generator, we suspect that internal waves and weather, which clearly can be a primary forcing in their own right, serve to modulate seiche amplitudes.

Specific to Monterey Bay, these results offer a simpler explanation for continuous seiche generation than the mesoscale gyre hypothesis proposed by Park et al. (2015), which lacked a physical mechanism to transfer energy into the bay, and is more energetically reasonable than the infragravity waves suggested by MacMahan (2015).

In the course of attributing tidal forcing as the driver of the observed shelf resonances, we introduced the idea of metamodes, dynamical modes of shelf-mode amplitude determined by empirical mode decomposition. The metamodes exhibited fortnightly modulation, and it is likely that examination of other metamode components may be useful towards understanding the dynamic behavior of modal structure in coastal environments.

Acknowledgements. We are indebted to Lawrence Breaker of Moss Landing Marine Laboratory for his identification of continuous seiche in Monterey Bay, his questioning of their origin, and fruitful discussions. We gratefully acknowledge additional citations on continuous seiche provided by an anonymous reviewer.

Edited by: J. M. Huthnance

\section{References}

Airy, G. B.: On the Tides at Malta, Philos. T. ROY. SOC., 169, 123 138, 1877.

Bellotti, G., Briganti, R., and Beltrami, G. M.: The combined role of bay and shelf modes in tsunami amplification along the coast, J. Geophys. Res., 117, C08027, doi:10.1029/2012JC008061, 2012.

Bloomfield, P.: Fourier Analysis of Time Series: An Introduction, 1st Edn., Wiley, New York, 261 pp., 1976.

Breaker, L. C., Broenkow, W. W., Watson, W. E., and Jo, Y.: Tida and non-tidal oscillations in Elkhorn Slough, California, Estuar. Coast., 31, 239-257, 2008.

Breaker, L. C., Tseng, Y., and Wang, X.: On the natural oscillations of Monterey Bay: observations, modeling, and origins, Prog. Oceanogr., 86, 380-395, doi:10.1016/j.pocean.2010.06.001, 2010.

Cartwright, D. E. and Young, M. Y.: Seiches and tidal ringing in the sea near Shetland, P. Roy. Soc. Lond. A Mat., 338, 111-128, 1974.

Chrystal, G.: On the hydrodynamical theory of seiches, T. Roy. Soc. Edin.-Earth, 41, 599-649, doi:10.1017/S0080456800035523, 1906.

Clarke, A. J. and Battisti, D. S.: The effect of continental shelves on tides, Deep-Sea Res., 28, 665-682, 1981.

Darwin, G. H.: The Tides and Kindred Phenomena in the Solar System, Houghton, Boston, 1899.

Forston, E. P., Brown, F. R., Hudson, R. Y., Wilson, H. B., and Bell, H. A.: Wave and surge action, Monterey Harbor, Monterey California, Tech. Rep. 2-301, United States Army Corps of Engineers, Waterways Experiment Station, Vicksburg, MS, 45 Plates, 1949.

Giese, G. S. and Chapman, D. C.: Coastal seiches, Oceanus, 36, 38-46, 1993

Giese, G. S., Chapman, D. C., Black, P. G., and Fornshell, J. A. Causation of large-amplitude coastal seiches on the Carribbean coast of Puerto Rico, J. Phys. Oceanogr., 20, 1449-1458, 1990.

Giese, G. C., Chapman, D. C., Collins, M. G., Encarnacion, R., and Jacinto, G.: The coupling between harbor seiches at palawan island and sulu sea internal solitons, J. Phys. Oceanogr., 28, 2418-2426, doi:10.1175/15200485(1998)028<2418:TCBHSA>2.0.CO;2, 1998.

Golmen, L. G., Molvir, J., and Magnusson, J.: Sea level oscillations with super-tidal frequency in a coastal embayment of western Norway, Cont. Shelf Res., 14, 1439-1454, doi:10.1016/02784343(94)90084-1, 1994.

Huang, N. E. and Wu, Z.: A review on Hilbert-Huang transform: method and its applications to geophysical studies, Rev. Geophys., 46, RG2006, doi:10.1029/2007RG000228, 2008.

Lowry, R., Pugh, D. T., and Wijeratne, E. M. S.: Observations of Seiching and Tides Around the Islands of Mauritius and Rodrigues, Western Indian Ocean Journal of Marine Science, 7, 15 28,2008

Lynch, T. J.: Long Wave Study of Monterey Bay, MS thesis, Naval Postgraduate School, Monterey, California, available at: calhoun.nps.edu/bitstream/handle/10945/15072/ longwavestudyofm00lync.pdf (last access: 3 March 2016), 1970. 
MacMahan, J.: Low-Frequency Seiche in a Large Bay., J. Phys. Oceanogr., 45, 716-723, doi:10.1175/JPO-D-14-0169.1, 2015.

Miles, J. and Munk, W.: Harbor paradox, J. Waterways Div.-ASCE, 87, 111-132, 1961.

Okihiro, M. and Guza, R. T.: Observation of seiche forcing and amplification in three small harbors, J. Waterw. Port C.-ASCE, 122, 232-238, 1996.

Park, J., Sweet, W. V., and Heitsenrether, R.: Water level oscillations in Monterey Bay and Harbor, Ocean Sci., 11, 439-453, doi:10.5194/os-11-439-2015, 2015.

Proudman, J.: Dynamical Oceanography, Methuen, London; Wiley, New York, 409 pp., 1953.

Rabinovich, A. B.: Seiches and Harbor Oscillations, in: Handbook of Coastal and Ocean Engineering, edited by: Young, C. K., World Scientific, Singapore, 193-236, 2009.

Shchepetkin, A. F. and McWilliams, J. C.: The regional oceanic modeling system (ROMS): a split-explicit, free-surface, topography-following-coordinate oceanic model, Ocean Model., 9, 347-404, doi:10.1016/j.ocemod.2004.08.002, 2005.
Taylor, G. I.: Tidal Friction in the Irish Sea, P. Roy. Soc. A-Math. Phy., 96, 330-330, doi:10.1098/rspa.1919.0059, 1919.

Thotagamuwage, D. T. and Pattiaratchi, C. B.: Influence of offshore topography on infragravity period oscillations in Two Rocks Marina, Western Australia, Coast. Eng., 91, 220-230, 2014.

Webb, D. J.: A model of continental-shelf resonances, Deep-Sea Res., 23, 1-15, 1976.

Wijeratne, E. M. S., Woodworth, P. L., and Pugh, D. T.: Meteorological and internal wave forcing of seiches along the Sri Lanka coast, J. Geophys. Res., 115, C03014, doi:10.1029/2009JC005673, 2010.

Woodworth, P. L., Pugh, D. T., Meredith, M. P., and Blackman, D. L.: Sea level changes at Port Stanley, Falkland Islands, J. Geophys. Res., 110, C06013, doi:10.1029/2004JC002648, 2005. 